\title{
Smoking zones versus smoke-free zones on Canadian post secondary campuses: Which zone is more effective, adhered to and preferred?
}

\author{
Matthew J. Fagan ${ }^{1 *}$, Taniya S. Nagpa ${ }^{2 *}$, Lyndsay Fitzgeorge ${ }^{3}$, William J. Smith², Josh Rosaasen ${ }^{2}$, Harry Prapavessis ${ }^{2}$
}

\begin{abstract}
INTRODUCTION This study aims to determine if smokers at post-secondary campuses are more likely to adhere to smoke-free zones (areas where smoking is not permitted) or smoking zones (areas where smoking is permitted) based on preference and effectiveness.

METHODS A self-reported survey was developed and administered at two postsecondary institutions; Western University (smoke-free zones) and Fanshawe College (smoking zones). Smokers were asked how often they use these zones, which zone is preferred and which zone they think is more effective. A chisquared analysis was performed to determine if there were differences in the frequency of responses.

RESULTS A total of 239 surveys were collected, 119 from Western and 120 from Fanshawe. Of these, $87 \%$ of respondents at Fanshawe were aware of where they could smoke on campus, and $67 \%$ reported that they mostly or always used these spaces. At Western, significantly fewer respondents knew where to smoke $(57 \%)$, and only $30 \%$ reported mostly or always using appropriate zones $(\mathrm{p}<0.05)$. More participants at Fanshawe indicated that they had been told by someone in authority where they could smoke $(36 \%)$ compared to Western $(19 \%, \mathrm{p}<0.05)$. At Fanshawe, $63 \%$ of respondents stated that smoking zones mostly or always effectively indicated where it was appropriate to smoke on campus compared to only $18 \%$ at Western $(\mathrm{p}<0.05)$. Both groups indicated they preferred the zone they currently had. Finally, more participants from Fanshawe intend to quit smoking within 6 months (61\% from Fanshawe vs 49\% from Western, p<0.05). CONCLUSIONS Smoking zones on post-secondary campuses may be more effective and adhered to by smokers than smoke-free zones.
\end{abstract}

\section{AFFILIATION \\ 1 POP PA Laboratory, School of Kinesiology, Faculty of Education, University of British Columbia, Vancouver, Canada \\ 2 Exercise and Health Psychology Laboratory, School of Kinesiology, Faculty of Health Sciences, University of Western Ontario, London, Canada \\ 3 Fitness and Health Promotion Program, School of Health Sciences, Faculty of Health, Community Studies \& Public Safety, Fanshawe College, London, Canada \\ * Contributed equally \\ CORRESPONDENCE TO Matthew J. Fagan. POP PA Laboratory, School of Kinesiology, Faculty of Education, University of British Columbia, Vancouver, Canada.E-mail:mfagan4@uwo.ca \\ KEYWORDS \\ cigarette smoking, university students, tobacco control, college students, smoking regulations}

Received: 29 August 2018 Revised: 1 March 2019

Accepted: 15 March 2019

\section{INTRODUCTION}

Smoking tobacco remains the leading cause of preventable death in North America ${ }^{1}$. Currently, in Canada, young adults (aged 20-24 years) are smoking at the highest prevalence compared to any other age group ${ }^{2}$. This high prevalence of smoking in the young adult population is coupled with very low cessation success ${ }^{3}$. Post-secondary institutions typically consist of students within the young adult age group, and therefore the tobacco control measures in place at these institutions are important to examine ${ }^{4}$.

In Canada, smoking is not permitted within ten meters of a public building ${ }^{5}$. This is nationally regulated and any violators are fined ${ }^{5}$. In addition to this law, Canadian universities and colleges may have institutional regulations for where smoking is or is not permitted on campus. In Canada, it is possible for institutions to elect to have their entire campus smoke-free (for example McMaster University ${ }^{6}$ ). Despite the potential positive influence on reducing 
smoking behaviour and secondhand smoke, research suggests campuses that are completely smoke-free face challenges including monitoring the campus to ensure that the policy is being implemented and followed, addressing safety concerns and relocation of the smoking behaviour elsewhere, with students having to leave campus to smoke ${ }^{7}$. Furthermore, Procter-Scherdtel and Collins ${ }^{7}$ highlighted the risky behaviour of persons on campus in avoiding being caught smoking and that banning smoking at a specific location can in turn just move the problem to other locations. Thus, a small percentage of campuses across the country have chosen to be completely smoke-free with a recent surge in policy change ${ }^{8}$. An alternative to this option that many campuses have chosen is to either have smoke-free zones (areas where smoking is not permitted on campus) or smoking zones (designated locations on campus where smoking is permitted). Research has not been conducted to determine if one option is superior to the other in terms of adherence to the designated zone, effectiveness and preference of zone.

Two post-secondary institutions located in the same city (London, Ontario, Canada) have opted to use either smoke-free zones or smoking zones. Western University (Western) currently has smokefree zones on campus. These areas are called 'blue zones' and they are identified by clearly marked blue lines on the concrete outlining the smoke-free area and 'no smoking' signs'. This tobacco control tactic has also been implemented at other institutions such as hospitals and has been shown to decrease the amount of smoking traffic and secondhand smoke in these spaces ${ }^{10,11}$. Studies that have evaluated the effectiveness of smoke-free zones on hospital properties, however, have included participants that are older than the average young adult population on post-secondary campuses. Fanshawe College (Fanshawe) uses smoking zones on campus. Throughout the campus, there are small areas in the shape of a box, with ashtrays and 'smoking area' signs indicating that this is a zone where smoking is permitted ${ }^{12}$. All other areas on campus have signs that display 'no smoking'. Strategies such as this one are often implemented in public spaces such as amusement parks and airports, but the effectiveness of and compliance with these zones have not been examined. Finally, smoke-free zones and smoking zones as methods for tobacco control on postsecondary institution campuses have yet to be compared in the literature.

Recent work done by Fitzgeorge et al. ${ }^{13}$ compared the demographics and attitudes on smokingrelated topics between smokers and non-smokers on a Canadian college campus (Fanshawe) and determined that differences were observed related to opinions on implementing smoking-regulations. Specifically, smokers were less likely to want a smoke-free campus than non-smokers. Research suggests that implementing health-related policies are less likely to succeed if the planning and implementation are not done in accordance with the preference of the target audience and specific health behaviour ${ }^{14}$. Therefore, if smokers indicate they do not want a smoke-free campus, they may be less likely to comply with the rules of a campus that implements this option.

This may also be related to message framing, comparing gain-frame versus loss-frame messaging. A gain-frame message focuses on the positive outcomes and suggests that you are given something whereas a loss-frame message suggests that there is a cost in not adopting a behaviour or something is taken away ${ }^{14}$. Previous research on other health-related behaviours including sunscreen use, increasing physical activity and smoking cessation have suggested that a gainframe message is more effective ${ }^{14,15}$. However, some behaviours have also shown improvement with loss-frame messaging such as cancer screening ${ }^{14}$ and vaccination compliance ${ }^{16}$. Smoking zones may represent gain-frame messaging, suggesting that you can smoke here and in doing so there is decreased secondhand smoke. Smoke-free zones may be a lossframe message suggesting that you cannot smoke here and therefore to reduce secondhand smoke you must take away smoking from the premise. Smoking cessation in the general population increased when gain-frame messaging was implemented ${ }^{14}$. However, as message framing may vary depending on the population and health behaviour being examined, it is important to determine if this trend would continue in the young adult population specifically focused on compliance to smoking areas on campus.

Furthermore, law enforcement may play an important role when determining the effectiveness of smoking zones compared to smoke-free zones. Work 
done by Rigotti et al. ${ }^{16}$ explored the effects of law enforcement on the sales of tobacco on adolescent smoking behaviour. It was found that environments with increased law enforcement of tobacco control laws had higher compliance by tobacco merchants. Research has not been done to compare the level of law enforcement in smoking zones and smokefree zones. The purpose of this study is, therefore, to examine the perceived effectiveness of smoking zones compared to smoke-free zones in terms of adherence, use and preference according to the opinions of the smokers that attend post-secondary institutions in Canada. It is hypothesized that the zone with greater reported law enforcement will have increased compliance and as a result will be considered more effective. Furthermore, as previous smoking cessation studies have suggested gain-frame messaging is preferred and smokers do not want a smoke-free campus, smoking zones will be more preferred over smoke-free zones.

\section{METHODS}

Two educational institutions, one that used smoking zones (Fanshawe) and one that used smoke-free zones (Western) were selected and compared. Both institutions are in London, Ontario, Canada. Fanshawe has approximately 21000 full-time students. Western has approximately 30000 full-time students. Students who identified as currently smoking, were $\geq 18$ years of age and attending one of the two sites were recruited for this study. Based on the work published by Fitzgeorge et al. ${ }^{13}$, the target sample size was 65 smokers from each site (total sample of 130 completed surveys). This study was approved by the Research and Ethics Boards of Western University and Fanshawe College.

A survey was developed that could be used at both sites (Appendix Item 1). The survey was made available to students via Survey Monkey, and paper copies were also distributed. Surveys were available and collected from October 2017 to April 2018. Students first reviewed a letter of information and provided informed consent before completing the survey. All survey responses were anonymous. The first question on the survey required participants to identify their institution. If a participant did not select Western or Fanshawe as the current educational institution, the survey responses were not included in the study. The survey collected the following sociodemographic information: age, sex, ethnicity, status on campus (full-time, parttime, faculty, staff, visitor), planned attempts to quit smoking in the next six months, and the total number of years smoked. To determine the perceived effectiveness of the smoking zones the following two questions requiring a yes or no answer were asked: 1) 'Have you been told where to smoke in the last year.', and 2) 'Do you know where to smoke?'. Additionally, the following three questions that provided a Likert-scale response (from $1=$ "not at all' to $5=$ 'always') were asked: 1) 'Do you use the designated areas to smoke.', 2) 'How effective are smoke-free areas', and 3) 'How effective are smoking-zones?'. Finally, participants were also asked to indicate if they prefer smoke-free zones or smoking zones on their campus. Participants were not compensated for their participation.

Age and the total number of years smoked were compared between the two groups using Student's t-test. Ethnicity, sex, status on campus, and attempting to quit smoking were compared using a chi-squared analysis. To determine the adherence to, effectiveness and preference of each zone, a chisquared analysis was performed to assess if there was a difference in the frequency of responses. For missing data (questions that were missed on the survey) an intent to treat analysis was performed by inputting the mean value for that group for all numerical outcomes. All statistical analyses were performed on SPSS Version 23.

\section{RESULTS}

A total of 239 completed surveys were collected, 119 from Western (smoke-free zones) and 120 from Fanshawe (smoking zones). Two submitted surveys (one from each site) were more than $50 \%$ incomplete and therefore were not included. There were no differences observed between the two groups for age, ethnicity, status on campus and the total number of years smoked. An intent to treat analysis was performed for missing data related to age (three missing values in total; two for surveys completed at Western, one from Fanshawe), this did not change the level of significance between the groups. There were more females who responded to the survey at Western (smoke-free zones) than at Fanshawe (smoking zones) (Table 1). 
Table 1. Participant sociodemographic information

\begin{tabular}{|c|c|c|}
\hline Characteristics & $\begin{array}{c}\text { Smoke free } \\
\text { zones } \\
\text { (Western, } \mathbf{n}=\mathbf{1 1 9}\end{array}$ & $\begin{array}{c}\text { Smoking zones } \\
\text { (Fanshawe, } \\
\text { n-120) }\end{array}$ \\
\hline Age, mean $\pm S D$ & $21.5 \pm 5.6$ & $23.2 \pm 5.2$ \\
\hline \multicolumn{3}{|l|}{ Sex, $n(\%)^{*}$} \\
\hline Male & 66 (55.5) & $83(69.2)$ \\
\hline Female & $46(38.7)$ & $36(3.00)$ \\
\hline Not disclosed & $7(5.8)$ & $1(0.8)$ \\
\hline \multicolumn{3}{|l|}{ Ethnicity, n (\%) } \\
\hline Caucasian & $79(66.4)$ & $70(58.3)$ \\
\hline Hispanic & $0(0)$ & $4(3.3)$ \\
\hline African American & $2(1.7)$ & $2(1.7)$ \\
\hline Asian & $24(20.2)$ & $24(20.0)$ \\
\hline Not disclosed & $14(11.7)$ & $20(16.7)$ \\
\hline \multicolumn{3}{|c|}{ Status on campus, $\mathrm{n}(\%)$} \\
\hline Full-time & $106(89.1)$ & 103 (85.8) \\
\hline Part-time & $6(5.0)$ & 15 (12.5) \\
\hline Faculty & $1(0.8)$ & $0(0)$ \\
\hline Staff & $4(3.4)$ & $1(0.8)$ \\
\hline Not disclosed & $2(1.7)$ & $1(0.8)$ \\
\hline $\begin{array}{l}\text { Number of years } \\
\text { smoked, mean } \pm \text { SD }\end{array}$ & $4.9 \pm 5.8$ & $6.1 \pm 7.6$ \\
\hline
\end{tabular}

More participants indicated that they knew where they could smoke at Fanshawe (smoking zones; 87\%) than at Western (smoke-free zones; 57\%, p<0.05). Similarly, more participants at Fanshawe indicated that they 'mostly' or 'always' used the designated smoking areas on campus than at Western (67\% compared to $30 \%$, respectively, $\mathrm{p}<0.05$ ). When asked if they found the designated smoking areas on their campus effective, more responses indicated that smoke-free zones (Western) are 'not at all' effective (45\%) than smoking zones (Fanshawe; $2.5 \%$, $\mathrm{p}<0.05$ ). More responses from Fanshawe (smoking zones) indicated that the smoking areas on campus were 'mostly' or 'always' effective (63\%) than the responses from Western (smoke-free zones; 18\%, $\mathrm{p}<0.05$ ). More participants at Fanshawe (smoking zones) indicated that they were told by someone in authority where they could smoke $(36 \%)$ compared to Western (smoke-free zones; 19\%, p<0.05).

When asked about preference of zones, participants indicated that the zone they currently have was more preferred. At Western, smoke-free zones were favoured by $62 \%$, whereas at Fanshawe $60 \%$ indicated that they preferred a smoking zone rather than a smoke-free zone $(\mathrm{p}<0.05)$. More participants indicated that they were considering a
Table 2. Questionnaire responses regarding attitudes towards zone use, perceived effectiveness and preference

\begin{tabular}{|c|c|c|}
\hline Questions* & $\begin{array}{c}\text { Smoke free } \\
\text { zones (Western, } \\
\text { n- 119) } \\
\text { n ( }(\%)\end{array}$ & 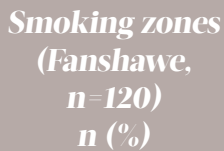 \\
\hline
\end{tabular}

\begin{tabular}{|c|c|c|}
\hline \multicolumn{3}{|c|}{$\begin{array}{l}\text { Do you know where you } \\
\text { can smoke on campus? }\end{array}$} \\
\hline Yes & $68(57.1)$ & 104 (86.6) \\
\hline No & $50(42.1)$ & 15 (12.5) \\
\hline Unanswered & $1(0.8)$ & $1(0.9)$ \\
\hline \multicolumn{3}{|c|}{$\begin{array}{l}\text { Do you use the } \\
\text { designated smoking } \\
\text { areas on your campus? }\end{array}$} \\
\hline Never & 35 (29.4) & $11(9.2)$ \\
\hline Rarely & 19 (16.0) & $8(6.7)$ \\
\hline Sometimes & $28(23.5)$ & $18(15.0)$ \\
\hline Mostly & $22(18.5)$ & 32 (26.7) \\
\hline Always & 14 (11.8) & $48(40)$ \\
\hline Unanswered & $1(0.8)$ & $3(2.4)$ \\
\hline \multicolumn{3}{|c|}{$\begin{array}{l}\text { Do you find the } \\
\text { designated smoking areas } \\
\text { on your campus effective? }\end{array}$} \\
\hline Always & $8(6.7)$ & 43 (35.7) \\
\hline Mostly & 13 (10.9) & 32 (26.7) \\
\hline Neutral & 15 (12.6) & 20 (16.7) \\
\hline Sometimes & $29(24.4)$ & 20 (16.7) \\
\hline Not at all & $54(45.4)$ & $3(2.5)$ \\
\hline Unanswered & $0(0)$ & $2(1.7)$ \\
\hline
\end{tabular}

Have you ever been told

by an authority figure

where you can or cannot

smoke on campus?

Yes

$\begin{array}{ll}23(19.3) & 43(35.8) \\ 96(80.7) & 77(64.2)\end{array}$

What type of zone

would you prefer on

your campus?

Smoke-free zones

$74(62.2)$

48 (40.0)

Smoking zones

45 (37.8)

$72(60.0)$

Are you considering a

quit attempt in the next

6 months?

Yes

No

$58(48.7)$

$73(60.8)$

$60(50.5)$

$45(37.5)$

Unanswered

$1(0.8)$

$2(0.170)$

${ }^{*} \mathrm{p}<0.05$. Chi-squared analysis performed for each question.

quit attempt within the next six months at Fanshawe (smoking zones; 61\%) than at Western (smokefree zones, $49 \%, \mathrm{p}<0.05$ ). All data pertaining to zone adherence, preference and effectiveness are presented in Table 2 . 


\section{DISCUSSION}

The results of the current study suggest that smoking zones on campus have greater self-reported compliance and may be perceived as more effective than smokefree zones. This is because more participants from Fanshawe (smoking zones) indicated that they were aware of where they were allowed to smoke and more likely to use these designated areas than participants from Western (smoke-free zones). Furthermore, participants with smoking zones indicated that they were more likely to have been told by someone in authority where they were allowed to smoke than participants that have smoke-free zones on their campus. Interestingly, when asked about preference of zones, results suggested that participants were more likely to prefer the current zone they have on their respective campus.

Previous literature on adherence to designated smoking areas has predominantly focused on a hospital setting. In Canada, hospital property is entirely smoke-free, which means that individuals must leave the hospital property in order to smoke ${ }^{10,11}$. A study that compared the effectiveness of hospitals with designated smoking areas and hospitals that were smoke-free found that compliance was higher at hospitals that have smoke-free zones ${ }^{18}$. The findings of the current study, however, suggest a different result as more participants from Fanshawe (smoking-zones) said they mostly or always used designated smoking areas than participants at Western (smoke-free zones). The difference in measurement tools used may explain the contradicting results. Dawley and Baldwin ${ }^{17}$ measured compliance to the zones by counting the number of individuals adhering to the designated smoking areas at various time points throughout the day, whereas the current study measured compliance to zone use with a self-reported Likert scale. Although the current study employed a self-reported measure, counting the number of individuals in each zone is also a challenge as it may not correctly capture an individual's usual behaviour but simply depending on the day and time the objective measure was taken.

Additionally, the presence of authorities monitoring and assuring that the zones are being used correctly may impact on adherence and effectiveness. Hospital-based studies have reported that smoke-free zones lack adherence if a staff member or someone in authority is not following regulations and is found smoking in areas where they should not be ${ }^{19}$. Furthermore, smoke-free zones at hospitals are more likely to be effective if someone in authority enforces the rules by ensuring that people who should not be smoking in that space are asked to leave $\mathrm{e}^{20,21}$. In the current study, it was found that fewer participants at Western (smoke-free zones) had been told by someone in authority where they could smoke compared with Fanshawe (smoking zones), which may potentially be why the smoke-free zones seemed to have less self-reported compliance and were ranked lower in terms of effectiveness.

Another potential explanation for why smoking zones seemed to be more effective may be related to message framing ${ }^{14}$. Framing a scenario as a 'loss' message has been shown to be less effective compared to a 'gain' message for preventative behaviours ${ }^{14}$. A meta-analysis completed by Gallagher and Updegraff ${ }^{14}$ reported that framing a scenario as a 'gain' message (i.e. you can smoke here) could produce positive self-efficacy, influence social norms and have a positive affect that could lead to uptake of the behaviour. This result was replicated in this study; it was shown that smokers at both institutions thought smoking zones (positivemessage framing: you can smoke here, by doing this you will reduce secondhand smoke) were more effective in telling people where they could smoke than smoke-free zones (negative-message framing: you cannot smoke here, by leaving the premise you will reduce secondhand smoke). Additionally, the institution with smoking zones reported a higher rate of self-reported compliance within these smoking zones than the institution with smoke-free areas. This is thought to be related to the Prospect Theory ${ }^{22}$, which states when individuals are faced with two choices - they can be influenced by their appraisal of personal risk and gain from their choice. For example, in the current study the risk is getting a fine from the authorities for smoking in an area where it is not allowed and the gain is protecting non-smokers from secondhand smoke. It has been documented that individuals typically favour messages that are framed to offer the highest gain at the lowest risk. This finding may provide evidence for supporting the implementation of smoking zones 
(positive-message framing) as more smokers may comply and use designated smoking areas correctly. This also has a positive implication for non-smokers as there would be a reduction of secondhand smoke in areas that are meant to be smoke-free.

Interestingly, even though participants at Western indicated that the smoke-free zones were not effective and not likely to use them, when asked about preference they still indicated they preferred smoke-free zones to smoking zones. At Fanshawe, smoking zones were more preferred. It may be that because they have only experienced one zone over the other, a true evaluation of their preference could not be assessed without diverse experience or an educational intervention. Finally, it was found that significantly more participants from Fanshawe intended to quit smoking within six months $(61 \%$ from Fanshawe vs $49 \%$ from Western, $\mathrm{p}<0.05$ ). This result should be interpreted with caution, as the study design does not allow for dissection of how either smoking zones impact on this result.

\section{Limitations and strengths}

This study is not without limitations. First, all data collected were self-reported by the smokers, which increases the risk for reporting bias. However, this study did use anonymous responses to minimize this. Additionally, using a subjective measure of an individual's perceptions of policy effectiveness is the quickest way to evaluate this question and it may highlight unintended changes of policy $2^{3}$. For example, resistance to the policy changes can potentially be highlighted through self-report while an objective measure of effectiveness would not capture this. Second, the data were only collected in London, Ontario (at both Fanshawe College and Western University) and therefore a larger more diverse sample of Canadian post-secondary institutions should be included in future work.

There are several strengths in this study that should be highlighted. This is the first study to compare smoke-free zones to smoking zones in the young adult population, who are currently smoking at the highest prevalence in Canada ${ }^{2}$. Second, these individuals came from university and college campuses and therefore these results can be generalized and used to inform tobacco control policies across Canadian campuses. Third, the study collected a larger sample than the target sample size of $n=130$.

\section{Future work}

The methodology used in this study can be used in future work with the aim to collect data across the country including different post-secondary sites. Additionally, the possibility of an educational intervention to increase the compliance and change smoker's negative attitudes towards smoke-free or smoking zone use warrants investigation. Consistent with the findings of Fitzgeorge et al. ${ }^{13}$, the majority of smokers questioned on either campus using smoking zones intended to quit. Future work comparing associations between different policies (smoking zones, smoke-free campuses, smoke-free zones) and the perceptions, attitudes, and behaviours of smokers planning a quit attempt could assist health promotion strategists to create optimal cessation environments and interventions.

\section{CONCLUSIONS}

The results of our study highlight differences between two post-secondary educational institutions with different tobacco control methods (smoking zones and non-smoking zones). It seems that smoking zones are more effective in terms of self-reported compliance and effectiveness. There was no difference in preference as participants preferred to keep the zone that was already implemented on their respective campus. Additionally, it seems that there is a greater presence of authorities policing smoking zones than non-smoking areas and this may be a contributing factor to the adherence of the zone. These results can be used by policy makers at Canadian post-secondary institutions to implement tobacco control tactics that take into consideration the perceptions of cigarette smokers on campus that may maximize compliance from the smokers and would create a campus that is suited for both smokers and non-smokers.

\section{REFERENCES}

1. World Health Organization. WHO Report on the Global Tobacco Epidemic. Vol 5.; 2013. doi:10.1002/aehe.3640230702

2. Government of Canada. Canadian Tobacco Use Monitoring Survey. Smoking in Canada: an overview. https://www.canada.ca/en/health-canada/services/ publications/healthy-living/canadian-tobacco-use- 
monitoring-survey-ctums-2012.html. Published 2012. Accessed July 2, 2018.

3. Backinger CL, Fagan P, Matthews E, Grana R. Adolescent and young adult tobacco prevention and cessation: current status and future directions. Tob Control. 2003;12 Suppl 4:IV46-V53. doi:10.1136/tc.12.suppl

4. Berger J. The Price of Knowledge. In: Berger J, Motte A, Parkin A, eds. The Price of Knowledge. 4th ed. Montreal: The Canada illlennium Scholarship Foundations; 2009.

5. Lemstra M, Neudorf C, Opondo J. Implications of a public smoking ban. Can J Public Heal Can Sante'e Publique. 2008;99(1):62-65.

6. McMaster University. Tobacco \& Smoke Free University Policy.; 2017. https://www.mcmaster.ca/policy/ Employee/Tobacco \& Smoke Free University Policy.pdf. Accessed August 29, 2018.

7. Procter-Scherdtel A, Collins D. Smoking restrictions on campus: Changes and challenges at three Canadian universities, 1970-2010. Heal Soc Care Community. 2013;21(1):104-112. doi:10.1111/j.1365-2524.2012.01094.x

8. Canadian Cancer Society. University and College 100\% Smoke-Free Campuses in Canada: National Status Report.; 2018. http://www.cancer.ca/ /media/cancer. $\mathrm{ca} / \mathrm{CW} /$ for media/Media releases/2018/Universitycollege-100-percent-smoke-free-campus-nationalreport-2018-09-14.pdf?la=en. Accessed August 29, 2018.

9. Western University. Let's Clear the Air Here. https:// www.uwo.ca/health/living_well/faculty_staff/lets_clear_ the_air_here.html. Published 2018. Accessed August 29, 2018.

10. Biener L, Abrams DB, Follick MJ, Dean L. A comparative evaluation of a restrictive smoking policy in a general hospital. Am J Public Health. 1989;79(2):192-195. doi:10.2105/AJPH.79.2.192

11. Nagle AL, Schofield MJ, Redman S. Smoking on hospital grounds and the impact of outdoor smoke-free zones. Tobacco Control. 1996;5:199-204. doi:10.1136/tc.5.3.199

12. Fanshawe College F. College Policy Manual: C206, ALCOHOL, DRUGS, ELEGTRONIC CIGARETTES TOBACCO PRODUCTS; 2016.

13. Fitzgeorge L, Tritter A, Fagan MJ, Nagpal TS, Prapavessis H. Informing population-specific smoking policy development for college campuses: An observational study. Tob. Prev. Cessation. 2018;4(July 26):1-8. doi:10.18332/tpc/92482

14. Gallagher KM, Updegraff JA. Health message framing effects on attitudes, intentions, and behavior: A metaanalytic review. Ann Behav Med. 2012;43(1):101-116. doi:10.1007/s12160-011-9308-7

15. Voss RP, Corser R, McCormick M, Jasper JD. Influencing health decision-making: A study of colour and message framing. Psychol Heal. 2018;33(7):941-954. doi:10.1080/08870446.2018.1453509

16. O'Keefe DJ, Nan X. The Relative Persuasiveness of Gainand Loss-Framed Messages for Promoting Vaccination: A
Meta-Analytic Review. Health Commun. 2012;27(8):776783. doi:10.1080/10410236.2011.640974

17. Rigotti NA, DiFranza JR, Chang Y, Tisdale T, Kemp $\mathrm{B}$, Singer DE. The effects of enforcing tobacco-sales laws on adolescents' access to tobacco and smoking behavior. N Engl J Med. 1997;337(15):1044-1015. doi:10.1056/nejm199710093371505

18. Dawley HH, Baldwin J. The Control of Smoking: Smoking Rate in Designated Smoking and No-Smoking Areas. Int J Addict. 1983;18(7). doi:10.3109/10826088309033070

19. Ratschen E, Britton J, McNeill A. Smoke-free hospitals The English experience: Results from a survey, interviews, and site visits. BMC Health Serv Res. 2008;8:1-9. doi:10.1186/1472-6963-8-41

20. Shipley M, Allcock R. Achieving a smoke-free hospital: Reported enforcement of smoke-free regulations by NHS health care staff. J Public Health (Bangkok). 2008;30(1):2-7. doi:10.1093/pubmed/fdn004

21. Schultz A, Finegan B, Nykiforuk C, Kvern M. A qualitative investigation of smoke-free policies on hospital property. C Can Med Assoc J. 2011;183(18):2085-2086. doi:10.1503/cmaj.111579

22. Tversky A, Kahneman D, Tversky A, Kahneman D. The Framing of Decisions and the Psychology of Choice The Framing of Decisions and the Psychology of Choice. 2007;211(4481):453-458. doi:10.1126/science.7455683

23. Paulhus D, Vazire S. Chapter 13 The Self-report method. In: Robins RW, Fraley RC, Krueger RF, eds. Handbook of Research Methods in Personality Psychology. New York: Guilford Press; 2007:244-239.

\section{CONFLICTS OF INTEREST}

The authors have completed and submitted the ICMJE Form for Disclosure of Potential Conflicts of Interest and none was reported.

FUNDING

There was no source of funding for this research.

PROVENANCE AND PEER REVIEW

Not commissioned; externally peer reviewed. 